\title{
BMJ Open Quality Enhancing the healthcare quality improvement storyboard using photovoice
}

\author{
Pamela Mathura, ${ }^{1}$ Miriam Li (D) , ${ }^{1}$ Natalie McMurtry, ${ }^{2}$ Narmin Kassam ${ }^{1}$
}

To cite: Mathura P, Li M, McMurtry N, et al. Enhancing the healthcare quality improvement storyboard using photovoice. BMJ Open Quality 2020;9:e01104. doi:10.1136/ bmjoq-2020-001104

Received 22 July 2020 Revised 5 October 2020 Accepted 14 0ctober 2020

Check for updates

(C) Author(s) (or their employer(s)) 2020. Re-use permitted under CC BY-NC. No commercial re-use. See rights and permissions. Published by BMJ.

${ }^{1}$ Department of Medicine, University of Alberta, Edmonton, Alberta, Canada

${ }^{2}$ University of Alberta, Edmonton, Alberta, Canada

Correspondence to

Pamela Mathura;

Pam.Mathura@albertahealthser vices.ca

\section{INTRODUCTION}

Visual photographic approaches have steadily gained momentum in health services research in the last 20 years; however, its use in quality improvement (QI) is sparse. ${ }^{1}$ Currently, the traditional A3 QI story board is an integral component for sharing health service improvement efforts. Named after the A3 international paper size of approximately 11" $\times 17^{\prime \prime}$, this one page/poster provides a visually concise synopsis of the problem, the root causes identified, the resolution and metrics that indicate resolution effect. ${ }^{2}$ The benefit of the A3 QI storyboard approach is in the thinking and behaviours it stimulates along with facilitating dialogue. ${ }^{3}$ Photovoice is a visual participatory method in which photographic images are taken to strengthen and supplement the more robust metrics involved in QI. ${ }^{4}$ The photographic image triangulates with the conventionally generated quantitative and qualitative findings to create a more comprehensive QI story. ${ }^{56}$ In QI studies that have used photographic images, the rationale for inclusion are, first, to alleviate challenges related to change acceptance as healthcare employees may gain a better understanding of why the improvement is a priority. Second, to facilitate collaboration between different stakeholder groups, and lastly the photographs may lead to a more direct understanding of people, their life experiences and perceptions enabling others to empathise and understand the QI effort. ${ }^{7}$

Within the setting of healthcare, engaging providers and patients, obtaining their buy-in and understanding their unique perspectives/experience are essential to improve the quality of care.$^{8-10}$ Here, we describe an initiative that undertook the inclusion of photovoice within the healthcare QI storyboard to convey the improvement effort beyond the usual narratives and metrics of a traditional A3 storyboard.

\section{METHODS}

In 2017, 17 QI projects within the Alberta Health Services (AHS) Medicine programme located in Edmonton, Alberta, Canada were invited to participate in this photovoice initiative. Each QI team was instructed to provide a photograph (taken with a personal camera or cellphone) and a brief vignette to support the usual poster presentation. Teams could take a maximum of four photographs, but was only allowed to select one for presentation based on a team consensus. The instructions for this task was presented both in person and via email along with a PowerPoint template to ease submission, but the instructions did not offer any specific examples or suggestions of photographic images to ensure creativity of submission.

The storyboards with photovoice included were presented at the annual AHS and University of Alberta Medicine QI Collaborative Day on 13 October 2017 to over 300 attendees (figure 1). One week after the event, an email seeking feedback was sent to all 17 participating QI team leads. Twelve team leads responded and agreed to provide feedback. Informal brief ( $5 \mathrm{~min}$ ) semistructured interviews with the team lead and A3 poster presenters were completed. The questions guiding this inquiry included: (1) what are your thoughts on completing the photo voice submission? (2) what were barriers and facilitators of the photovoice approach and A3 inclusion? (3) what feedback was obtained from the attendees of the QI day that viewed the A3 poster? The textual data collected during the interviews were captured verbatim on paper initially and all responses were then compiled into a single Microsoft word document. Our project lead (PM) independently completed a modified sentiment analysis ${ }^{11}{ }^{12}$ categorising all sentiments, totalling 72, as either positive or negative for each question. 


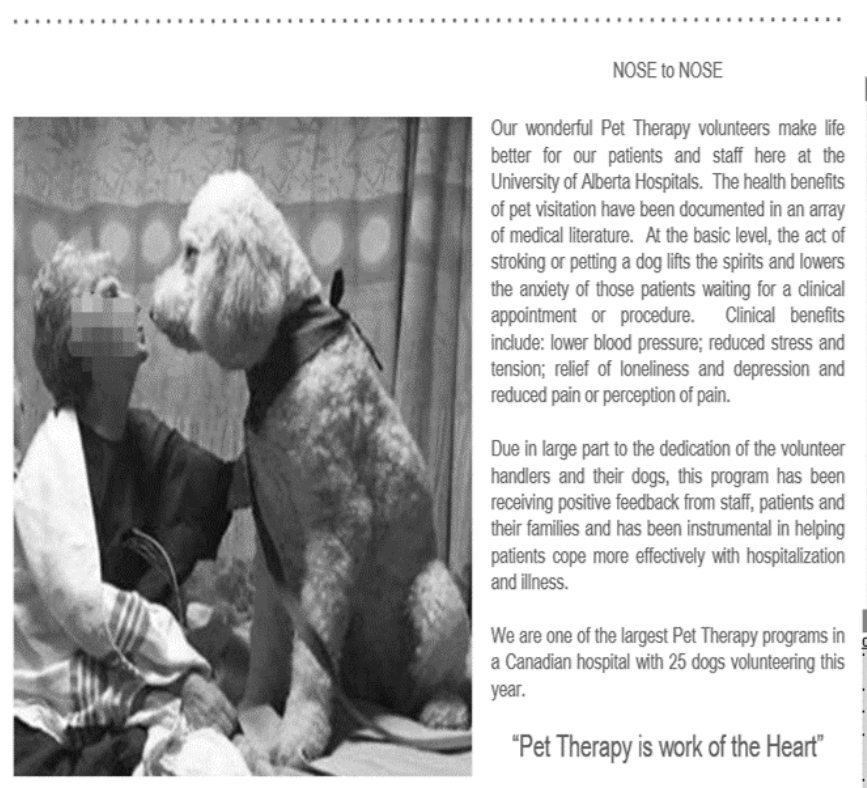

Pet Therapy Team Volunteer Resources

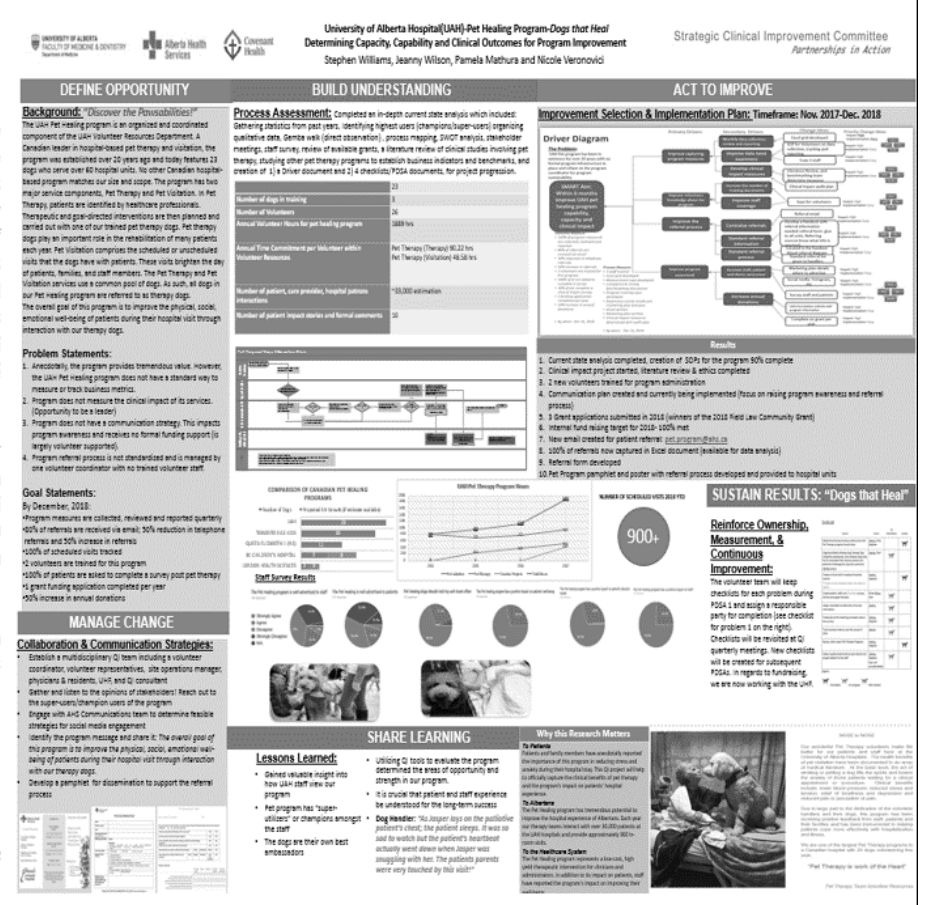

Figure 1 This photovoice captures the patient experience along with the vignette, which shares program specifics. A viewer of this A3 storyboard stated- "this makes me smile, patients need this program". Verbal permission was attained from the featured individual for publication of this image.

\section{RESULTS}

The feedback obtained from 12 participating QI teams regarding the photovoice method were overall positive sentiments $(61 / 72)$. Presenters perceived that this method allowed QI teams to artistically describe patients' or healthcare providers' experiences and perceptions. However, a concern consistently (10/12 QI team leads) mentioned was the struggle to determine a singular picture that captured the main QI message. A key barrier perceived were competing priorities of clinical duties and the additional task of taking photographs. Also, writing the vignette came easier for some teams compared with others. The absence of rigid rules improved completing this task and the provided template eased presentation.

The presenters' perception of the anecdotal feedback received from QI day attendees who reviewed the storyboards indicated that the addition of the photographic image and vignette stimulated an empathic response, aided in explaining why the QI project was important and that the image provided a person-centred approach that the traditional A3 storyboards lacked.

\section{CONCLUSION}

A critical aspect of improvement storytelling, the person experience and perspective, has been omitted in the traditional A3 QI storyboard. The addition of lived experience through photovoice provides a more comprehensive overview of healthcare QI.
In our experience, the use of photovoice enhanced the presentation of QI data by eliciting an empathetic response from the viewer. This is comparable to the response prior research teams have received. Halvorsrud et al used photovoice to tell the story of ethnic minority people's struggle with mental illness, ${ }^{8}$ Balbale et al enlightened the public on the perspectives of healthcare employees, ${ }^{9}$ and Kramer et al used photovoice to create a successful community health campaign. ${ }^{10}$ The use of photographic approaches in aforementioned projects allowed for greater engagement of participants and stakeholders with the identified problem, making it an invaluable addition to any QI project. Limitations of this initiative was that we did not complete a robust formal evaluation, indirect feedback was obtained from reviewers of the posters, recall bias from the QI team leads, and one member of our team independently reviewed the textual responses. We plan to continue with the photovoice addition to QI posters, with a focus on implementation and sustainability by strengthening the evaluation with real-time feedback cards placed next to the QI posters for reviewers to complete along with photovoice questionnaires to be completed by all the QI team members. To mitigate the barriers identified, we plan on developing photovoice guidelines, providing examples of photographs with the vignette from past projects and assigning one person within the QI team 
to lead this activity. We hope this initiative serves to inspire others to creatively include the person experience and to demonstrate how to bring healthcare QI storytelling to life.

Acknowledgements The authors thank all the Alberta Health Services QI team members fortheir participation and dedication to sharing the person characteristics of improvement.

Contributors PM is the corresponding author and both PM and NM are credited for the conception, design, and data collection. ML and PM conducted the data analysis and interpretation and created the manuscript. NK critically revised the manuscript and oversaw the design of the study and data collection. All authors edited and approved the final manuscript.

Funding The authors have not declared a specific grant for this research from any funding agency in the public, commercial or not-for-profit sectors.

Competing interests None declared.

Patient and public involvement Patients and/or the public were not involved in the design, or conduct, or reporting, or dissemination plans of this research.

Patient consent for publication Not required.

Provenance and peer review Not commissioned; externally peer reviewed.

Open access This is an open access article distributed in accordance with the Creative Commons Attribution Non Commercial (CC BY-NC 4.0) license, which permits others to distribute, remix, adapt, build upon this work non-commercially, and license their derivative works on different terms, provided the original work is properly cited, appropriate credit is given, any changes made indicated, and the use is non-commercial. See: http://creativecommons.org/licenses/by-nc/4.0/.

ORCID iD

Miriam Li http://orcid.org/0000-0002-4082-0607

\section{REFERENCES}

1 Papoulias C. Showing the unsayable: participatory visual approaches and the constitution of 'patient experience' in healthcare quality improvement. Health Care Anal 2018;26:171-88.

2 Winner LE, Burroughs TJ, Cady-Reh JA, et al. Use of cascading A3s to drive systemwide improvement. Jt Comm J Qual Patient Saf 2017;43:422-8.

3 Sobek DK. Understanding A3 thinking: a critical component of Toyota's PDCA management system. CRC Press, 2008.

4 Wang CC. Photovoice: a participatory action research strategy applied to women's health. J Womens Health 1999;8:185-92.

5 Balbale SN, Locatelli SM, LaVela SL. Through their eyes: lessons learned using participatory methods in health care quality improvement projects. Qual Health Res 2016;26:1382-92.

6 Donetto S, Pierri P, Tsianakas V, et al. Experience-based Co-design and healthcare improvement: Realizing participatory design in the public sector. Design J 2015;18:227-48.

$7 \mathrm{Close} \mathrm{H}$. The use of photography as a qualitative research tool. Nurse Res 2007:15:27-36.

8 Halvorsrud K, Rhodes J, Webster GM, et al. Photovoice as a promising public engagement approach: capturing and communicating ethnic minority people's lived experiences of severe mental illness and its treatment. BMJ Open Qual 2019;8:e000665.

9 Balbale SN, Turcios S, LaVela S. Health care employee perceptions of patient-centered care: a Photovoice project. Qual Health Res 2015;25:417-25.

10 Kramer L, Schwartz P, Cheadle A, et al. Promoting policy and environmental change using photovoice in the Kaiser Permanente community health Initiative. Health Promot Pract 2010;11:332-9.

11 Greaves F, Ramirez-Cano D, Millett C, et al. Use of sentiment analysis for capturing patient experience from free-text comments posted online. J Med Internet Res 2013;15:e239-9.

12 Bandorski D, Kurniawan N, Baltes P, et al. Contraindications for video capsule endoscopy. World J Gastroenterol 2016;22:9898-908. 